\title{
Presence of Gamma-Aminobutyric Acid (Gaba) in the Pedal Mucus of the Critically Endangered Species Patella ferruginea
}

\author{
G. A. Rivera-Ingraham ${ }^{1,2}$ - F. Espinosa ${ }^{3} \cdot$ B. Krock $^{2}$
}

Received: 18 December 2014 / Revised: 16 March 2015 /Accepted: 8 April 2015 /Published online: 24 April 2015

(C) Springer Science+Business Media New York 2015

\begin{abstract}
Patella ferruginea is a giant patellid limpet endemic to the Mediterranean Sea. It presently is in danger of extinction, and many have called for developing conservation measures including the mass production of spats for reintroduction projects. However, so far all attempts have been relatively unsuccessful. Previous work analyzing the effects of gamma-aminobutyric acid (GABA) on the recruitment of patellid limpets has shown that larvae respond to the presence of this signaling molecule. This response could explain the gregarious distribution typical of this species. In the present study, we demonstrated that GABA is naturally secreted by $P$. ferruginea in the pedal mucus. GABA is preferentially secreted during the summer, coinciding with the reproductive resting period of the species. Further research should aim to analyze the effects of GABA on larval development and metamorphosis in order to assess its potential use to improve conservation efforts.
\end{abstract}

Keywords Chemical cues $\cdot$ Limpet $\cdot$ Mucus $\cdot$ Recruitment

G. A. Rivera-Ingraham

Georgina.Rivera-Ingraham@univ-montp2.fr

1 Groupe fonctionnel AEO (Adaptation Ecophysiologique et Ontogenèse), UMR 9190 MARBEC, Place Eugène Bataillon, 34095 Montpellier Cedex 05, France

2 Alfred Wegener Institute Helmholtz Centre for Polar and Marine Research, Am Handelshafen 12, 27570 Bremerhaven, Germany

3 Laboratorio de Biología Marina, Departamento de Zoología, Universidad de Sevilla, Avenida Reina Mercedes 6, 41012 Sevilla, Spain

\section{Introduction}

Settlement by active habitat selection is common in nature and may involve chemical cues produced by conspecifics that attract the larvae to favorable conditions (e.g., Pawlik 1992). A variety of chemicals can act as signals to induce metamorphosis, including gamma-aminobutyric acid (GABA), which has been identified as an important signal compound in gastropods (e.g., García-Lavandeira et al. 2005; Laimek et al. 2008; Rivera-Ingraham et al. 2011).

The ferruginean limpet (Patella ferruginea Gmelin, 1791) is the most endangered macroinvertebrate in the western Mediterranean, and the reinforcement of populations and/or reintroduction of specimens to areas where the species is in danger of extinction has been proposed as a conservational tool (MMAMRM 2008). Rivera-Ingraham et al. (2011) examined whether GABA enhanced the recruitment of several limpet species (including $P$. ferruginea) to artificial plates used as units for reintroduction. The study highlighted how the application of GABA in intertidal areas enhanced recruitment of limpet larvae and caused settlement to start earlier than in controls. Under natural conditions $P$. ferruginea settles gregariously. GABA had effects on the settlement of larvae similar to the presence of adult conspecifics (Rivera-Ingraham et al. 2011), thus indicating that the adults may be a source of signaling chemicals that stimulate settlement. In this study, we aimed to determine if GABA is naturally present in the pedal mucus of $P$. ferruginea and to detect possible changes related to size and reproductive cycle.

\section{Methods and Materials}

The study was conducted in Ceuta, Strait of Gibraltar, home to one of the most important remaining populations of 
P. ferruginea and also populated by Cymbula nigra. Limpets were collected from an area known as "Parque del Mediterráneo", inaccessible to the public and thereby housing major populations of these two species.

We used a group size of 18 P. ferruginea ( 9 males and 9 females; average size $=6.73 \pm 1.44 \mathrm{~cm}$ and $8.22 \pm 0.65 \mathrm{~cm}$, respectively) and $6 \mathrm{C}$. nigra limpets ( 3 males and 3 females; average size $=7.4 \pm 0.11 \mathrm{~cm}$ and $7.83 \pm 0.20 \mathrm{~cm}$, respectively) serving as controls. In 2012, coinciding with the reproductive period of P. ferruginea (December) (Frenkiel 1975), animals were removed carefully from the rock with a spatula during low tide. Mucus samples were taken by allowing limpets to move for $30 \mathrm{~min}$ over the surface of a glass petri dish, big enough to allow the animal to move and leave a trail of pedal mucus (Donovan and Carefoot 1997). Animals were marked individually with an epoxy tag (as in Espinosa et al. 2008) and were then returned to their home scars, ensuring that they fully re-adhered to avoid their loss.

Previously marked limpets were retrieved in July 2013 (14 out of 18), coinciding with the reproductive resting period of P. ferruginea, and were subjected to the same procedure.

Petri dishes containing mucus samples were allowed to dry at RT for $48 \mathrm{hr}$. The dry surface was scraped with a sterilized razor blade, and the mucus sample was weighed and preserved at $-20{ }^{\circ} \mathrm{C}$ until further analyses.

Samples were diluted in 200-400 $\mu \mathrm{l}$ MilliQ water and intensively vortexed. Mass spectral measurements to quantify GABA content were performed on a triple quadrupole mass spectrometer (API 4000 QTrap, AB Sciex, Darmstadt, Germany) equipped with a Turbo Ion Spray interface, coupled to a liquid chromatograph (model 1100, Agilent, Waldbronn, Germany). The liquid chromatograph includes a solvent reservoir, in-line degasser (G1379A), binary pump (G1311A), refrigerated autosampler (G1329A/G1330B), and temperature-controlled column oven (G1316A). Mass spectrometric analyses for paralytic shellfish toxins (PSTs) were performed on a hydrophilic interaction liquid ion chromatography (HILIC) stationary phase. The analytical column (150× $4.6 \mathrm{~mm}$ ) was packed with $5 \mu \mathrm{m}$ ZIC-HILIC (Merck, Darmstadt, Germany) and maintained at $35^{\circ} \mathrm{C}$. The flow rate was $0.7 \mathrm{ml} \mathrm{min}{ }^{-1}$ and gradient elution performed with eluent A ( $2 \mathrm{mM}$ formic acid and $5 \mathrm{mM}$ ammonium formate in acetonitrile in water $(80: 20 \mathrm{v} / \mathrm{v}))$ and eluent B $(10 \mathrm{mM}$ formic acid and $10 \mathrm{mM}$ ammonium formate in water). The gradient process involved: 20 min column equilibration using $80 \%$ eluent A solution, linear gradient for 5 min reaching $65 \%$ eluent A, 10 min for a $40 \%$ eluent $\mathrm{A}$ concentration, and one min for returning to initial conditions (total run time: $36 \mathrm{~min}$ ).

Selected reaction monitoring experiments were performed in the positive ion mode. Three transitions were used: $\mathrm{m} / \mathrm{z}$ $104>87$ (for quantification), $104>86$ and $104>69$ (for quality controls). Dwell times of $20 \mathrm{~ms}$ were used for each transition. The source parameters were: curtain gas (10 psi), temperature $\left(550{ }^{\circ} \mathrm{C}\right)$, ion spray voltage $(5500 \mathrm{~V})$, gas $1(30 \mathrm{psi})$, gas 2 (40 psi), interface heater (off), collision gas (medium), declustering potential $(26 \mathrm{~V})$, entrance potential $(10 \mathrm{~V})$, collision cell exit potential $(12 \mathrm{~V})$, and collision energies $(15 \mathrm{~V}$ for the transitions $\mathrm{m} / \mathrm{z} 104>87$ and $104>86$, whereas $45 \mathrm{~V}$ for $\mathrm{m} / \mathrm{z}$ $104>69$ ). Samples were calibrated against an external three point curve consisting of GABA standards of 20, 200, and $1000 \mathrm{pg} \mathrm{l}^{-1}$. The limit of detection (LOD) was determined as $35 \mathrm{pg} \mathrm{\mu l}^{-1}$ (signal-to-noise, $\mathrm{S} / \mathrm{N}=3$ ).

Data was analyzed through the non-parametric test of Kruskal-Wallis with SPSS $15.0^{\circ}$ (SPSS Inc., IL, USA). All values are given as average \pm S.E.M.

\section{Results}

All analyses conducted on $C$. nigra had GABA levels below the LOD. For $P$. ferruginea, the levels were below the LOD for 16/19 samples taken during winter (reproductive season) and 5/14 samples taken during the summer (resting season).

Patella ferruginea pedal mucus contained a significantly higher amount of GABA during the resting season (40.59 \pm 14.44 pmol per mg mucus) than during the reproductive period $(3.12 \pm 1.60$ pmol per mg mucus) $(K=13.63 ; P<0.001)$. No correlation was found with the size of the individuals (Fig 1a). Mucus production was higher during winter (37.02 \pm $5.11 \mathrm{mg}$ mucus per $\mathrm{h}$ ) than during summer $(24.71 \pm$ $5.47 \mathrm{mg}$ mucus per $\mathrm{h})(K=4.367 ; P<0.05)$ but showed no correlation with limpet size (Fig $1 \mathrm{~b}$ ).

\section{Discussion}

Since the work of Morse et al. (1979) describing the effects of GABA on the settlement of Haliotis rufescens larvae, many authors have reported this and other compounds to have larvae-attracting properties in a wide variety of species (see review by Pawlik 1992). For the family Patellidae, only one study by Rivera-Ingraham et al. (2011) experimentally tested the effects of GABA on limpet behavior and recruitment. With the present study we confirm that GABA is naturally secreted in the pedal mucus of P. ferruginea, reinforcing the hypothesis that chemical cues, and GABA in particular, play a role in the species life cycle.

Sexually mature $P$. ferruginea can be found in Ceuta from late September to the end of February (personal observation) so settlement should start in January as suggested by Frenkiel (1975). The small size of the new settlers makes it difficult to detect them before they reach a size of about $4 \mathrm{~mm}$, which in natural conditions should take around 2.7 months for animals located inside the port of Ceuta (Espinosa et al. 2008) where our animals were taken. The fact that $P$. ferruginea individuals secrete higher levels of GABA during the reproductive resting 
Fig. 1 Data for all analyzed individuals as a function of the size of the limpet at the beginning of the experiment (T0). a) GABA content (pmol per mg mucus) in the pedal mucus of Patella ferruginea $b$ ) mucus production by the animals (mg mucus per $\mathrm{h}$ ). Squares and circles represent males and females, respectively. Black and white symbols correspond to the samples collected during the reproductive period (December 2012) and the resting period (July 2013), respectively. All samples under the LOD are marked as zero
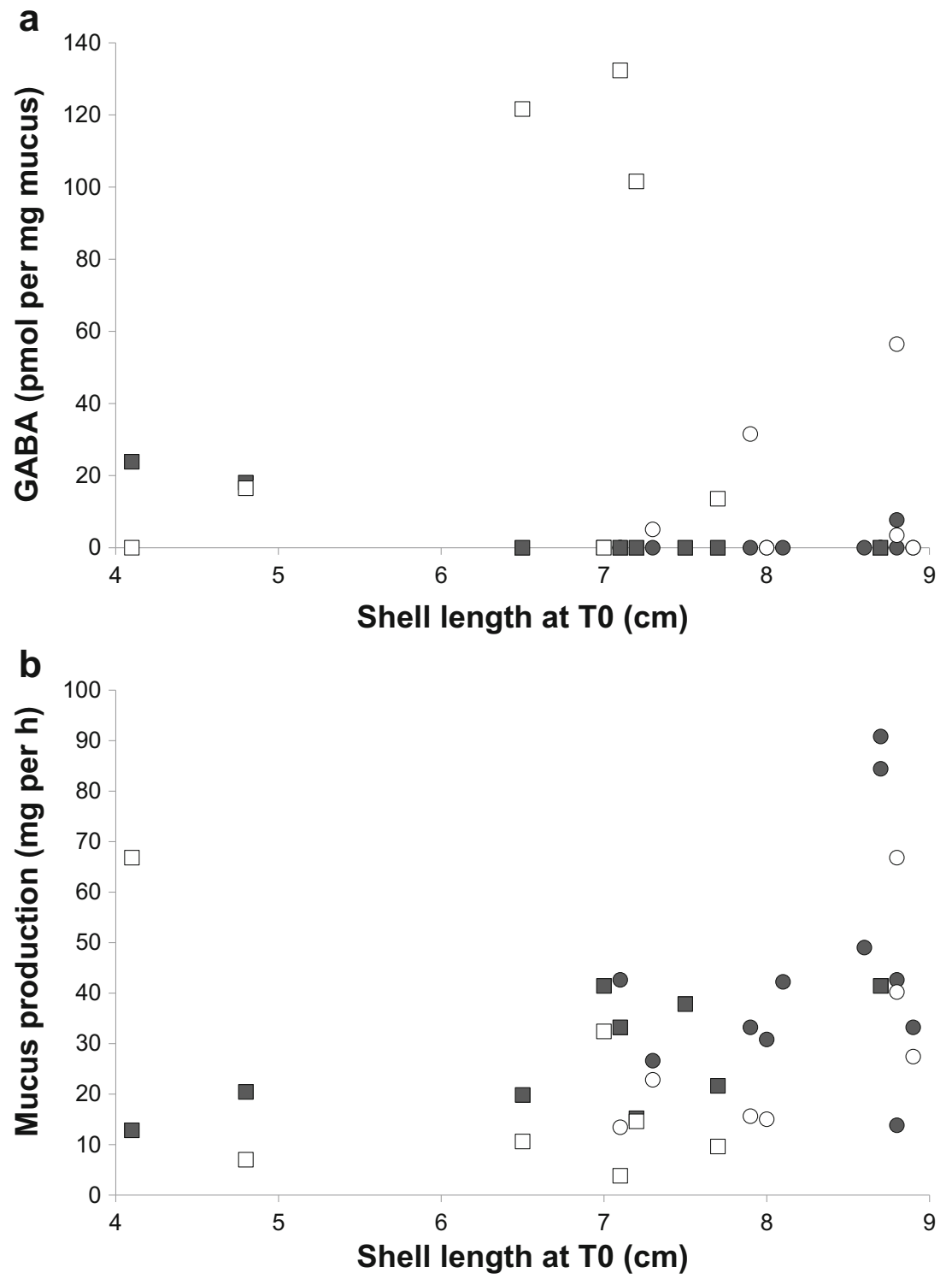

period would enhance settlement process after the release of gametes during the reproductive period.

Since GABA is a metamorphosis inducer of important commercial species such as Mytilus galloprovincialis or Ostrea edulis (García-Lavandeira et al. 2005), much effort has been directed towards the application of GABA to largescale aquaculture production. In the same line, our results may be of use in the mass production of $P$. ferruginea spats for conservation purposes. Spain, being one of the few European countries where important $P$. ferruginea populations can still be found, developed a conservation strategy (MMAMRM 2008) highlighting the necessity of creating a captive breeding program to produce juveniles for their reintroduction in the natural habitat. Despite intense efforts by different research groups to produce juveniles in captivity, success rates have been low (Guallart et al. 2013). We hypothesize that, as for other mollusks like the Haliotis sp., larvae may require the stimulation effect of specific chemical cues (Hooker and Morse 1985) like GABA, without which fewer than $1 \%$ of larvae will eventually complete metamorphosis and survive (Morse 1984). We, thus, suggest that further aquaculture research should test the effect of GABA in P. ferruginea larval development and behavior since this compound seems to play a major role in the final stages of larval development and settlement in nature.

Acknowledgments This study was partially funded by a postdoctoral fellowship of the Fundación Ramón Areces awarded to G.A. RiveraIngraham. Additional funding was provided by the HGF (Helmholtz Association of German Research Centres) through the research programme PACES II. We thank Enrique Ostalé Valriberas for help in the sampling process, the Consejería de Medio Ambiente de Ceuta- 
OBIMASA staff for support, and two anonymous referees for useful comments on the original manuscript.

\section{References}

Donovan DA, Carefoot TH (1997) Locomotion in the abalone Haliotis kamschatkana: pedal morphology and cost of transport. J Exp Biol 200:1145-1153

Espinosa F, González AR, Maestre MJ, Fa D, Guerra-García JM, GarcíaGómez JC (2008) Responses of the endangered limpet Patella ferruginea to reintroduction under different environmental conditions: survival, growth rates and life history. Ital J Zool 75:371-384

Frenkiel L (1975) Contribution a l'étude des cycles de reproduction des Patellidae en Algérie. PSZ Napoli 39:153-189

García-Lavandeira M, Silva A, Abad M, Pazos AJ, Sánchez JL, Parallé L (2005) Effects of GABA and epinephrine on the settlement and metamorphosis of the larvae of four species of bivalve molluscs. J Exp Mar Biol Ecol 316:149-156

Guallart J, Peña JB, Pérez-Larruscaín J, Calvo M, Acevedo I (2013) Estrategias para la obtención mediante técnicas de acuicultura de juveniles de Patella ferruginea (Mollusca, Patellidae), especie "en peligro de extinción" y valoración de su uso para la conservación.
Paper presented at the XIV Congreso Nacional de Acuicultura. Gijón, Spain

Hooker N, Morse DE (1985) Abalone: the emerging development of commercial cultivation in the United States. In: Huner JV, Brown EE (eds) Crustacean and mollusc aquaculture in the United States. AVI Publishers, Westport, pp 365-413

Laimek P, Clark S, Stewart M, Pfeffer F, Wanichanon C, Hanna P, Sobhon P (2008) The presence of GABA in gastropod mucus and its role in inducing larval settlement. J Exp Mar Biol Ecol 354:182191

MMAMRM (2008) Estrategia de conservación de la lapa ferrugínea (Patella ferruginea). Conferencia sectorial de Medio Ambiente. Ministerio de Medio Ambiente, Medio Rural y Marino, Madrid

Morse DE (1984) Biochemical and genetic engineering for improved production of abalones and other valuable molluscs. Aquaculture 39:263-282

Morse DE, Hooker N, Duncan H, Jensen L (1979) Gamma-aminobutyric acid, a neurotransmitter induces planktonic abalone larvae to settle and begin metamorphosis. Science 204:407-410

Pawlik JR (1992) Chemical ecology of the settlement of benthic marine invertebrates. Oceanogr Mar Biol Annu Rev 30:273-335

Rivera-Ingraham GA, Espinosa F, García-Gómez JC (2011) Effect of $\gamma$ amino butyric acid on limpet populations: towards the future management and conservation of endangered patellid species. J Chem Ecol 37:1-9 